\title{
Endovascular Management of Intracranial Atherosclerotic Stenosis: Lessons from Mistakes in the Past and how to Achieve Improved Outcomes
}

\author{
Hans Henkes ${ }^{1,2}$ - Pervinder Bhogal ${ }^{3}$. Victoria Hellstern ${ }^{1} \cdot$ Hansjörg Bäzner ${ }^{4}$ \\ Accepted: 9 February 2021 \\ (c) The Author(s) 2021
}

\section{Why Dealing with Intracranial Atherosclerotic Stenosis?}

The term intracranial atherosclerotic stenosis (ICAS) refers to the lumen loss or occlusion of an intracranial artery due to an atherosclerotic plaque. With the widespread use of transcranial Doppler ultrasonography (TCD), computed tomography angiography (CTA), and magnetic resonance angiography (MRA), the prevalence of ICAS has increased during the last 25 years. About $8-10 \%$ of ischemic strokes in Europeans are now related to ICAS, with significantly higher numbers in African Americans, Asians, and Hispanics. The occurrence of ICAS is associated with advanced age, diabetes mellitus, arterial hypertension, peripheral atherosclerosis, and coronary heart disease. An ICASinduced stroke can be due to arterio-arterial emboli, thrombotic vessel occlusion, hemodynamic compromise, perforator occlusion, and any combination thereof [1].

The WASID trial compared high-dose aspirin and monitored warfarin to treat $\geq 50 \%$ large intracranial vessel atherosclerotic stenosis. During a mean follow-up of 1.8 years, the rate of ischemic stroke in an artery's supply territory with atherosclerotic stenosis was $15 \%$ and $12 \%$, respectively [2]. In the SAMMPRIS trial, the primary endpoint was any stroke or death within 30 days after enrolment, ischemic stroke in the qualifying artery territory beyond 30 days of enrolment, or any stroke or death

Hans Henkes

hhhenkes@aol.com

1 Neuroradiologische Klinik, Katharinenhospital, Klinikum Stuttgart, Kriegsbergstraße 60, 70194 Stuttgart, Germany

2 Medical Faculty, University Duisburg-Essen, Essen, Germany

3 Department of Interventional Neuroradiology, The Royal London Hospital, London, UK

4 Neurologische Klinik, Katharinenhospital, Klinikum Stuttgart, Kriegsbergstraße 60, 70194 Stuttgart, Germany within 30 days after a revascularization procedure. During a median follow-up of 32.4 months, a primary endpoint event occurred in $15 \%$ of the patients undergoing aspirin and clopidogrel medication plus management of vascular risk factors and lifestyle modification [3].

\section{Medicinal Treatment}

Warfarin has been shown to carry higher hemorrhagic risks than antiplatelet medication without added protective value against ischemic events [2]. The Platelet-Oriented Inhibition in New TIA and Minor Ischemic Stroke (POINT) trial compared aspirin alone versus clopidogrel plus aspirin for the secondary prevention after minor stroke or transient ischemic attack (TIA). The inclusion criteria did not address ICAS specifically. Clopidogrel plus aspirin and aspirin alone were associated with $5 \%$ and $6.5 \%$ major ischemic events, respectively. Major hemorrhage occurred in $0.9 \%$ and $0.4 \%$, respectively [4].

In the SAMMPRIS trial, patients received $325 \mathrm{mg}$ aspirin daily for the duration of the follow-up (and probably beyond) plus $75 \mathrm{mg}$ clopidogrel daily for 90 days. This medication's impact remains challenging to determine since the patients were also subject to lifestyle modification and vascular risk factor management [1]. Ticagrelor and prasugrel in secondary stroke prevention in patients with symptomatic ICAS are not yet well defined.

\section{Endovascular Treatment}

Interventional cardiology techniques mainly influenced the underlying concept of treating high-grade ICAS by endovascular means. During the initial phase of this experience, dedicated balloon catheters for intracranial angioplasty were not yet available [5]. If well-selected patients were treated in experienced centers, high success rates and 
severe complication rates below $10 \%$ were achieved with balloon-expandable coronary stents $[6,7]$. It became evident that the results in terms of periprocedural safety were good in elective cases, while the acute stroke setting was associated with a much higher complication rate [8]. The Pharos Vitesse stent (Micrus) was the first balloon-expandable stent with a dedicated indication for ICAS and was a derivative of a coronary stent. The initial results were quite promising [9]. In the VISSIT trial, patients were randomized for balloon-expandable stent treatment plus medical treatment or medical treatment alone. The stent group patients had a significantly higher rate of primary safety endpoint occurrence than the patients in the medical arm, including an $8.6 \%$ rate of intracranial hemorrhage [10]. A similar sequence of results had previously been observed for the Wingspan stent (Stryker). This is a combination of a non-compliant balloon and a self-expanding nitinol stent. The stent structure is the same as Neuroform, but the radial force is increased [11]. Again, the initial results were good, even though a completely new treatment technique had to be adopted [12]. In the SAMMPRIS trial medical treatment with aspirin and clopidogrel, vascular risk factor management and lifestyle modification were randomized against the same regimen plus balloon angioplasty and Wingspan implantation. In the Wingspan vs. the conservative management groups, any stroke rate was $26 \%$ vs. $19 \%$, with hemorrhage rates of $13 \%$ vs. $4 \%$, respectively [3]. Besides, follow-up examinations revealed a high rate of symptomatic in-stent stenosis of $14 \%$ at 3 years [13]. Concerns related to methodological aspects of SAMMPRIS have been published [14, 15]. On 15 September 2016, the Federal Joint Committee (Gemeinsamer Bundesausschuss) on behalf of the German Federal Ministry of Health ruled that the usage of stents for the treatment of intracranial stenosis is no longer covered by the health insurance companies concerned [16]. Exempted are patients with $a \geq 70 \%$ intracranial stenosis who had an infarct related to this stenosis and suffered from a second infarct despite intensive medical treatment. In addition, patients with an acute intracranial occlusion without a therapeutic alternative or after the failure of such an alternative are also included in the exemption.

\section{Future Directions}

The current issue of Clinical Neuroradiology features three original articles dealing with the treatment of ICAS. Wang et al. used drug-coated balloons (DCB) without stenting in 35 patients and encountered significant complications in 2 $(5.7 \%)$ patients [17]. In a similar study, Remonda et al. also used DCBs with only 2/33 (6\%) intracranial complications without severe clinical sequelae. They reported, however, a $12 \%$ rate of symptomatic restenosis [18]. Guan et al. were able to demonstrate the spatial relationship between atherosclerotic plaques of the proximal middle cerebral artery and the origin of the lenticulostriate perforators [19]. These three papers illustrate the current attempts to improve the diagnosis and endovascular treatment of patients with ICAS.

There are several lessons learned from previous randomized trials and published papers.

Conservative management is a viable option for many patients and should be the first step, typically based on dual antiplatelet medication, monitored by adequate response tests (e.g., VerifyNow) to identify non-responders.

Qualification of the interventionist is a delicate subject. Annual minimum quantities of specific procedures per interventionist could be a means to avoid the risks associated with so-called low-volume centers. Active quality (i.e., outcome) management with external auditing would be a further step ahead.

Timing of the endovascular treatment is crucial, and procedures within the first day(s) after the index event are hazardous [20].

Logistics are of utmost importance. Patients with ICAS need continuous monitoring and aggressive blood pressure management after the removal of the intracranial stenosis. To some extent, systolic blood pressure below $120 \mathrm{~mm} \mathrm{Hg}$ is a safeguard against reperfusion hemorrhage [21].

The morphology and anatomy of ICAS plaques are to a certain extent varied. It is unlikely that a single device or method can address different target lesion types. For many intradural stenoses (e.g., M1 segment), balloon angioplasty without a stent is a good option [22]. Drug-eluting balloonexpandable stents are frequently perfect for petrous internal carotid artery and intradural vertebral artery stenoses [23]; however, perforator basilar artery strokes with an associated atherosclerotic plaque are better treated with a Solitaire stent alone [24].

Technical developments for advanced treatment of ICAS are pending. The DSA-based vessel diameter measurements are frequently inaccurate, causing sizing mistakes in the balloon diameter selection. Dual antiplatelet medication is required for all possible stents and increases the risk of hemorrhagic complications. Stents, both balloon-expandable and self-expanding, with reduced surface thrombogenicity, would allow treatment under single antiplatelet medication [25].

Future trials will primarily address patients after failed medical treatment. For the time being, endovascular treatment as a first-line therapeutic option will be difficult to justify, given the good results of conservative management. A randomized trial comparing medical vs. endovascular treatment is currently beyond the horizon. 


\section{Declarations}

Conflict of interest $\mathrm{H}$. Henkes is co-founder and shareholder of phenox $\mathrm{GmbH}$, femtos $\mathrm{GmbH}$, and CONTARA GmbH. P. Bhogal and V. Hellstern have a consulting agreement with phenox GmbH. H. Bäzner has no competing interests.

Ethical standards This article did not require data collection from individual patients or animals. The authors assume that cited articles are following the concerning ethical standards. Several of the mentioned treatment concepts represent off-label use of specific medical devices.

Open Access This article is licensed under a Creative Commons Attribution 4.0 International License, which permits use, sharing, adaptation, distribution and reproduction in any medium or format, as long as you give appropriate credit to the original author(s) and the source, provide a link to the Creative Commons licence, and indicate if changes were made. The images or other third party material in this article are included in the article's Creative Commons licence, unless indicated otherwise in a credit line to the material. If material is not included in the article's Creative Commons licence and your intended use is not permitted by statutory regulation or exceeds the permitted use, you will need to obtain permission directly from the copyright holder. To view a copy of this licence, visit http://creativecommons.org/licenses/by/4. $0 /$.

\section{References}

1. Hurford R, Rothwell PM. Prevalence, prognosis, and treatment of atherosclerotic intracranial stenosis in Caucasians. Int J Stroke. 2020. https://doi.org/10.1177/1747493020974461. Epub ahead of print.

2. Chimowitz MI, Lynn MJ, Howlett-Smith H, Stern BJ, Hertzberg VS, Frankel MR, Levine SR, Chaturvedi S, Kasner SE, Benesch CG, Sila CA, Jovin TG, Romano JG; Warfarin-Aspirin Symptomatic Intracranial Disease Trial Investigators. Comparison of warfarin and aspirin for symptomatic intracranial arterial stenosis. N Engl J Med. 2005;352:1305-16.

3. Derdeyn CP, Chimowitz MI, Lynn MJ, Fiorella D, Turan TN, Janis LS, Montgomery J, Nizam A, Lane BF, Lutsep HL, Barnwell SL, Waters MF, Hoh BL, Hourihane JM, Levy EI, Alexandrov AV, Harrigan MR, Chiu D, Klucznik RP, Clark JM, McDougall CG, Johnson MD, Pride GL Jr, Lynch JR, Zaidat OO, Rumboldt Z, Cloft HJ; Stenting and Aggressive Medical Management for Preventing Recurrent Stroke in Intracranial Stenosis Trial Investigators. Aggressive medical treatment with or without stenting in high-risk patients with intracranial artery stenosis (SAMMPRIS): the final results of a randomised trial. Lancet. 2014;383:333-41.

4. Johnston SC, Easton JD, Farrant M, Barsan W, Conwit RA, Elm JJ, Kim AS, Lindblad AS, Palesch YY; Clinical Research Collaboration, Neurological Emergencies Treatment Trials Network, and the POINT Investigators. Clopidogrel and Aspirin in acute ischemic stroke and high-risk TIA. N Engl J Med. 2018;379:215-25.

5. Berg-Dammer E, Henkes H, Weber W, Berlit P, Kuhne D. Percutaneous transluminal angioplasty of intracranial artery stenosis: clinical results in 24 patients. Neurosurg Focus. 1998;5:e13.

6. Suh DC, Kim JK, Choi JW, Choi BS, Pyun HW, Choi YJ, Kim MH, Yang HR, Ha HI, Kim SJ, Lee DH, Choi CG, Hahm KD, Kim JS. Intracranial stenting of severe symptomatic intracranial stenosis: results of 100 consecutive patients. AJNR Am J Neuroradiol. 2008;29:781-5.

7. Vajda Z, Miloslavski E, Güthe T, Schmid E, Schul C, Albes G, Henkes $\mathrm{H}$. Treatment of intracranial atherosclerotic arterial stenoses with a balloon-expandable cobalt chromium stent (Coroflex Blue): procedural safety, efficacy, and midterm patency. Neuroradiology. 2010;52:645-51.

8. Dorn F, Prothmann S, Wunderlich S, Liebig T. Stent angioplasty of intracranial stenosis: single center experience of 54 cases. Clin Neuroradiol. 2012;22:149-56.

9. Kurre W, Berkefeld J, Sitzer M, Neumann-Haefelin T, du Mesnil de Rochemont R. Treatment of symptomatic high-grade intracranial stenoses with the balloon-expandable Pharos stent: initial experience. Neuroradiology. 2008;50:701-8.

10. Zaidat OO, Fitzsimmons BF, Woodward BK, Wang Z, KillerOberpfalzer M, Wakhloo A, Gupta R, Kirshner H, Megerian JT, Lesko J, Pitzer P, Ramos J, Castonguay AC, Barnwell S, Smith WS, Gress DR; VISSIT Trial Investigators. Effect of a balloon-expandable intracranial stent vs medical therapy on risk of stroke in patients with symptomatic intracranial stenosis: the VISSIT randomized clinical trial. JAMA. 2015;313:1240-8.

11. Krischek O, Miloslavski E, Fischer S, Shrivastava S, Henkes H. A comparison of functional and physical properties of self-expanding intracranial stents [Neuroform3, Wingspan, Solitaire, Leo+, Enterprise]. Minim Invasive Neurosurg. 2011;54:21-8.

12. Bose A, Hartmann M, Henkes H, Liu HM, Teng MM, Szikora I, Berlis A, Reul J, Yu SC, Forsting M, Lui M, Lim W, Sit SP. A novel, self-expanding, nitinol stent in medically refractory intracranial atherosclerotic stenoses: the Wingspan study. Stroke. 2007;38:1531-7.

13. Derdeyn CP, Fiorella D, Lynn MJ, Turan TN, Cotsonis GA, Lane BF, Montgomery J, Janis LS, Chimowitz MI; SAMMPRIS Investigators. Nonprocedural symptomatic infarction and instent restenosis after intracranial angioplasty and stenting in the SAMMPRIS trial (Stenting and Aggressive Medical Management for the Prevention of Recurrent Stroke in Intracranial Stenosis). Stroke. 2017;48:1501-6.

14. Henkes H, Bäzner H, Nelson PK. Comment on: Stenting versus aggressive medical therapy for intracranial arterial stenosis: Chimowitz MI, Lynn MJ, Derdeyn CP, et al. N Engl J Med. 2011;365:993-1003. Clin Neuroradiol. 2011;21:257-9.

15. Abou-Chebl A, Steinmetz H. Critique of "Stenting versus aggressive medical therapy for intracranial arterial stenosis" by Chimowitz et al in the new England Journal of Medicine. Stroke. 2012;43:616-20.

16. Bundesministerium für Gesundheit. Bekanntmachung eines Beschlusses des Gemeinsamen Bundesausschusses über eine Änderung der Richtlinie Methoden Krankenhausbehandlung: Einsatz von Stents zur Behandlung intrakranieller arterieller Stenosen vom: 15. September 2016. BAnz AT 22.12.2016 B2. 2016.

17. Wang AY, Chang $\mathrm{CH}$, Chen $\mathrm{CC}$, Wu YM, Lin CM, Chen CT, Hsieh PC. Leave nothing behind: treatment of intracranial atherosclerotic disease with drug-coated balloon angioplasty. Clin Neuroradiol. 2020. https://doi.org/10.1007/s00062-020-00935-w. Epub ahead of print.

18. Remonda L, Diepers M, Berberat J, Kahles T, Anon J, Nedeltchev K, Gruber P. Drug-coated balloon treatment in symptomatic intracranial high grade stenosis: a retrospective study of 33 patients. Clin Neuroradiol. 2020. https://doi.org/10.1007/s00062-020-00936-9. Epub ahead of print.

19. Guan M, Lin J, Huang S, Leng X, Shi C, Qiao H, Wang X, Huang L. High-degree middle cerebral artery stenosis: can advanced 3D DSA-MRI fusion imaging better illustrate plaques and perforators? Clin Neuroradiol. 2020. https://doi.org/10.1007/s00062-02000927-w. Epub ahead of print.

20. Jiang WJ, Cheng-Ching E, Abou-Chebl A, Zaidat OO, Jovin TG, Kalia J, Hussain MS, Lin R, Malik AM, Hui F, Gupta R. Multicenter analysis of stenting in symptomatic intracranial atherosclerosis. Neurosurgery. 2012;70:25-30; discussion 31.

21. Ghuman M, Tsang ACO, Klostranec JM, Krings T. Sentinel Angiographic Signs of Cerebral Hyperperfusion after Angioplasty and 
Stenting of Intracranial Atherosclerotic Stenosis: A Technical Note. AJNR Am J Neuroradiol. 2019;40:1523-5.

22. Dumont TM, Sonig A, Mokin M, Eller JL, Sorkin GC, Snyder KV, Hopkins LN, Levy EI, Siddiqui AH. Submaximal angioplasty for symptomatic intracranial atherosclerosis: a prospective Phase I study. J Neurosurg. 2016;125:964-71.

23. Vajda Z, Aguilar M, Göhringer T, Horváth-Rizea D, Bäzner H, Henkes H. Treatment of intracranial atherosclerotic disease with a balloon-expandable paclitaxel eluting stent: procedural safety, efficacy and mid-term patency. Clin Neuroradiol. 2012;22:227-33.
24. Cao X, Wang J, Tian C, Du Z, Su H, Liu X, Lv B, Yu S, Chen X, Hui F. Solitaire AB stent-angioplasty for stenoses in perforator rich segments: A single-center experience. Interv Neuroradiol. 2020;26:608-14.

25. Lenz-Habijan T, Brodde M, Kehrel BE, Bannewitz C, Gromann K, Bhogal P, Aguilar Perez M, Monstadt H, Henkes H. Comparison of the thrombogenicity of a bare and antithrombogenic coated flow diverter in an in vitro flow model. Cardiovasc Intervent Radiol. 2020;43:140-6. 